\title{
Glomerular basement membrane synthesis and serum concentration of type IV collagen in streptozotocin-diabetic rats
}

\author{
Ch. Hasslacher ${ }^{1}$, R. Reichenbacher ${ }^{1}$, F. Gechter ${ }^{1}$ and R. Timp ${ }^{2}$ \\ ${ }^{1}$ Department of Internal Medicine, University of Heidelberg and ${ }^{2}$ Max Planck-Institut for Biochemistry, Martinsried (Munich), FRG
}

\begin{abstract}
Summary. Glomerular basement membrane synthesis was measured in vivo in diabetic rats at various times after streptozotocin injection. Simultaneously the type IV collagen concentration in serum was determined by a radioimmunoassay specific for the terminal cross-linking domain, $7 \mathrm{~S}$ collagen. Basement membrane collagen synthesis and the $7 \mathrm{~S}$ collagen levels were markedly raised in diabetic animals 18-34 days after streptozotocin injection and showed a significant correlation. The results suggest that the amount of serum $7 \mathrm{~S}$ collagen
\end{abstract}

reflects increased basement membrane synthesis in a diabetic situation. Both basement membrane collagen synthesis and serum $7 \mathrm{~S}$ collagen concentration also show a positive correlation with the blood glucose levels of diabetic rats. This indicates that the degree of metabolic dysregulation influences basement membrane synthesis.

Key words: Basement membrane synthesis, type IV collagen, $7 \mathrm{~S}$ collagen, diabetes, streptozotocin.
Diabetes mellitus is a disease in which the structure and function of the capillary basement membrane is substantially changed. This membrane is composed of collagenous and non-collagenous proteins. The major collagen type IV is assembled in a regular network with individual molecules linked together at one terminal region by a disulphide rich domain, $7 \mathrm{~S}$ collagen [19]. 7S collagen can be solubilized from basement membranes by proteolysis and occurs in almost all basement membranes [13]. It is a potent immunogen and cross-reacting material has been detected in serum and other biological fluids by radioimmunoassay [14]. An increased 7S collagen level was demonstrated recently in the serum of diabetic rats, which was well controlled after treatment with insulin [15]. The reason for the elevated concentration of this basement membrane component is still not clear. In the present study, we have compared the serum concentration of $7 \mathrm{~S}$ collagen with the activity of basement membrane synthesis in renal glomeruli of diabetic rats at various times after injection of streptozotocin.

\section{Materials and methods}

Male Wistar rats (aged 6-8 weeks, $160-180 \mathrm{~g}$ ) were rendered diabetic by IP injection of streptozotocin $(75 \mathrm{mg} / \mathrm{kg}$ body weight). These rats were selected at random from a group of the same age and sex. The remaining animals were kept as non-diabetic controls. All animals received chow pellets and water ad libitum.

Four, 18 or 34 days after diabetes induction, blood glucose determinations were performed in diabetic and control rats one day before injection of the radioisotope by using a glucose oxidase kit (Boehringer, Mannheim, FRG). Animals with similar glucose levels and body weight were pooled ( $n=4-5$ rats) and were injected with a single IP dose of L- $\left(2,3-{ }^{3} \mathrm{H}\right)$-proline (New England Nuclear, Boston, Massachusetts, USA). Diabetic and non-diabetic animals received $150 \mu \mathrm{Ci} / 100 \mathrm{~g}$ body weight of the tracer. Forty-two hours after injection of the radioisotope, the animals were killed and the kidneys were removed immediately and placed on ice. Blood was collected from each rat. After clotting at room temperature, sera were stored at $-25^{\circ} \mathrm{C}$.

\section{Isolation and analyses of basement membrane}

Glomeruli were isolated using a sieve technique described previously [5] and basement membranes were then purified according to the detergent method of Meezan et al. [8]. Isolated basement membranes were hydrolysed with $6 \mathrm{~mol} / \mathrm{l} \mathrm{HCl}$ for $24 \mathrm{~h}$ at $110^{\circ} \mathrm{C}$. An aliquot of the hydrolysate (containing $0.04-0.06 \mathrm{mg}$ basement membrane) was placed on an amino acid analyser (LKB 4400, LKB Biochrom, Cambridge, UK) for determination of amino acids. ${ }^{3} \mathrm{H}$-proline and ${ }^{3} \mathrm{H}$-hydroxy-proline were measured in another aliquot of the hydrolysate which was passed over a column of Dowex 50-X12 (Serva, Heidelberg, FRG) using $1 \mathrm{~mol} / 1 \mathrm{HCl}$ as eluant as described by Brownlee and Spiro [2]. Radioactivity was determined in a liquid scintillation counter (Betaszint BF 5000, Berthold, Wildbad, FRG). Phosphorous content of isolated basement membranes was measured according to Bartlett [1]. 
Table 1. Body weight, blood glucose, serum creatinine and proline concentrations in the diabetic and non-diabetic rats studied

\begin{tabular}{|c|c|c|c|c|c|c|c|}
\hline Rats & $\begin{array}{l}\text { Age } \\
\text { (weeks) }\end{array}$ & $\begin{array}{l}\text { Duration of } \\
\text { diabetes } \\
\text { (days) }\end{array}$ & $\begin{array}{l}\text { Number of } \\
\text { experi- } \\
\text { ments/rats }\end{array}$ & $\begin{array}{l}\text { Body weight } \\
\text { (g) }\end{array}$ & $\begin{array}{l}\text { Blood glucose } \\
(\mathrm{mmol} / 1)\end{array}$ & $\begin{array}{l}\text { Creatinine } \\
(\mu \mathrm{mol} / 1)\end{array}$ & $\begin{array}{l}\text { Proline } \\
(\mu \mathrm{mol} / \mathrm{l})\end{array}$ \\
\hline Non-diabetic & 7 & & $6 / 24$ & $172 \pm 26$ & $4.99 \pm 0.39$ & $35.36 \pm 4.42$ & $177.52 \pm 38.53$ \\
\hline Diabetic & 11 & 18 & $3 / 15$ & $173 \pm 18$ & $17.15 \pm 2.61$ & $44.20 \pm 6.18$ & $172.24 \pm 16.85$ \\
\hline Diabetic & 11 & 34 & $3 / 15$ & $177 \pm 16$ & $17.87 \pm 2.10$ & $53.04 \pm 6.18$ & $181.07 \pm 26.95$ \\
\hline
\end{tabular}

Results are expressed as mean $\pm \mathrm{SD}$; each experiment containing four to five rats

Table 2. Amino acid composition and phosphorus content of isolated basement membranes of rats at various ages and duration of diabetes

\begin{tabular}{|c|c|c|c|c|c|}
\hline & & \multicolumn{2}{|l|}{ Diabetic rats } & \multicolumn{2}{|c|}{ Non-diabetic rats } \\
\hline $\begin{array}{l}\text { Amino acids (residues } / 1000 \\
\text { amino acid residues) }\end{array}$ & $\begin{array}{l}\text { Hydroxyproline } \\
\text { Proline } \\
\text { Glycine } \\
\text { Hydroxylysine } \\
\text { Lysine }\end{array}$ & $\begin{array}{r}80.3 \pm 4.9 \\
84.4 \pm 8.1 \\
192.1 \pm 9.7 \\
24.9 \pm 3.2 \\
28.8 \pm 4.3\end{array}$ & $\begin{array}{r}82.4 \pm 6.2 \\
85.3 \pm 7.2 \\
200.2 \pm 12.4 \\
24.2 \pm 4.1 \\
26.9 \pm 5.2\end{array}$ & $\begin{array}{r}78.7 \pm 6.3 \\
83.6 \pm 7.1 \\
195.3 \pm 11.3 \\
23.1 \pm 5.1 \\
26.8 \pm 4.7\end{array}$ & $\begin{array}{r}79.2 \pm 7.1 \\
85.4 \pm 6.9 \\
193.0 \pm 10.8 \\
25.0 \pm 3.9 \\
27.9 \pm 4.5\end{array}$ \\
\hline $\begin{array}{l}\text { Phosphorus content } \\
\text { ( } \mu \mathrm{g} / 100 \mathrm{mg} \text { basement } \\
\text { membrane })\end{array}$ & & $40 \pm 6$ & $38 \pm 6$ & $38 \pm 5$ & $41 \pm 6$ \\
\hline
\end{tabular}

Results are expressed as mean $\pm \mathrm{SD}$ of six experimental and control groups (each containing four to five rats)

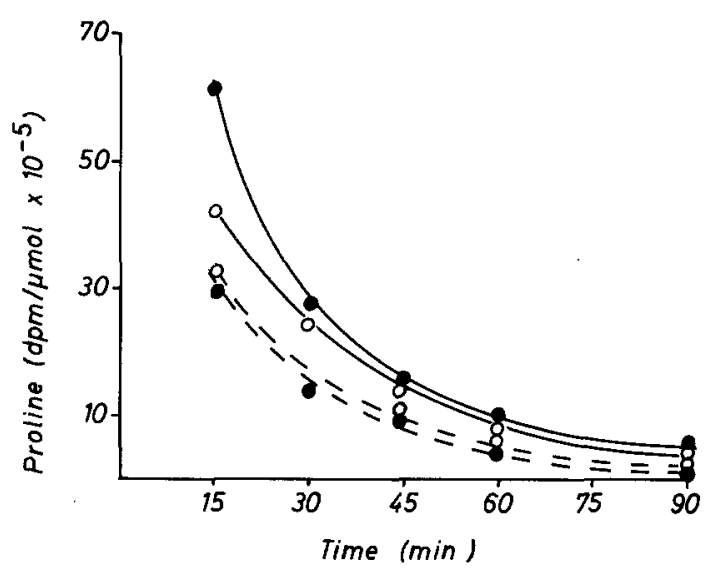

Fig. 1. Specific activity of free proline in sera of normal (-) and diabetic rats (-.) at various times after injection of ${ }^{3} \mathrm{H}$-proline $(150 \mu \mathrm{Ci} / 100 \mathrm{~g}$ body weight). Data were obtained in 7 week- $(O)$ and 11 week- (O) old normal rats and with diabetic rats of the same age 4 days $(O)$ or $18-34$ days $(-)$ after streptozotocin injection

\section{Measurement of specific activity of proline in serum}

Determination of specific activity of proline in the serum of diabetic and non-diabetic rats was performed according to the method of Brownlee and Spiro [2] with minor modifications. After injection of ${ }^{3} \mathrm{H}$-proline $(150 \mu \mathrm{Ci} / 100 \mathrm{~g}$ body weight $)$, blood was taken from the tail vein at various time intervals up to $90 \mathrm{~min}$. The animals were then killed by aortic puncture. Blood collected at this time was taken for the determination of the proline content of the serum. All sera were deproteinized with $5 \%$ sulphosalicylic acid. Proline radioactivity in the deproteinized sera was measured by thin layer chromatography on silica gel sheets (Schleicher and Schüll, Kassel, FRG) in a solvent containing t-butylalcohol, ethylmethylketon, water and ammonium hydroxide $(80: 60: 50: 8, \mathrm{v} / \mathrm{v})$. Total proline content of the sera was determined by an amino acid analyser (LKB 4400, LKB Biochrom, Cambridge, UK). Zero time values were extrapolated from a semilogarithmic plot of the specific activities.

\section{Determination of $7 S$ collagen and statistical methods}

Type IV collagen concentration in the serum was measured by a radioimmunoassay specific for $7 \mathrm{~S}$ collagen [14]. This assay shows complete cross-reacting with intact type IV collagen [19] and with the precursor from type IV procollagen [10]. The Wilcoxon test was used for statistical evaluation.

\section{Results}

The streptozotocin-injected rats were markedly hyperglycaemic, but had only slightly increased in weight compared with control rats. Concentrations of serum proline and creatinine were similar in the diabetic and non-diabetic groups (Table 1). After IP injection of ${ }^{3} \mathrm{H}$ proline, the serum radioactivity declined rapidly in diabetic and non-diabetic rats, and after $90 \mathrm{~min}$ amounted to only $3 \%-5 \%$ of the zero time value. The specific activity of serum proline was distinctly lower in diabetic than non-diabetic rats (Fig. 1). This difference was therefore accounted for by calculation of the radioactivity incorporated into the basement membrane as de- 
Table 3. Specific activities of proline and hydroxyproline in the isolated basement membranes and serum concentrations of $7 \mathrm{~S}$ collagen at various ages and duration of diabetes in diabetic and non-diabetic rats

\begin{tabular}{lclllc}
\hline Rats & $\begin{array}{l}\text { Age } \\
\text { (weeks) }\end{array}$ & $\begin{array}{l}\text { Duration of } \\
\text { diabetes } \\
\text { (days) }\end{array}$ & $\begin{array}{l}\text { Number of } \\
\text { experi- } \\
\text { ments/rats }\end{array}$ & $\begin{array}{l}\text { Proline } \\
(\mathrm{dpm} / \mu \mathrm{mol})\end{array}$ & $\begin{array}{l}\text { Hydroxyproline } \\
(\mathrm{dpm} / \mu \mathrm{mol})\end{array}$ \\
\hline Diabetic & 7 & 4 & $6 / 24$ & $12582 \pm 3215$ & $9796 \pm 2712$ \\
$(\mathrm{ng} / \mathrm{ml})$
\end{tabular}

Results are expressed as mean $\pm \mathrm{SD}$; each experiment containing four to five rats. $\mathrm{dpm}=$ desintegrations $/ \mathrm{min}$

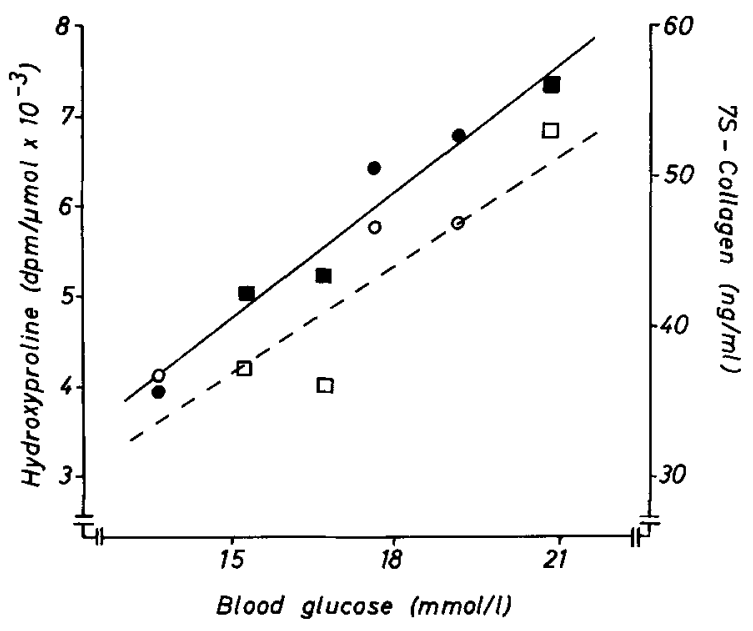

Fig. 2. Correlation between collagen synthesis in renal basement membranes $(\boldsymbol{Q}, \mathbf{a})$ or serum concentration of $7 \mathrm{~S}$ collagen $(O, \square)$ and blood glucose levels in diabetic rats. Collagen synthesis was measured by determining specific activity of hydroxyproline. Blood glucose concentration was determined 1 day before injection of radioisotope. Each point represents the results of a pooled group of five animals from experiments after $18(\bullet, O)$ or $34(\square, \square)$ days of diabetes

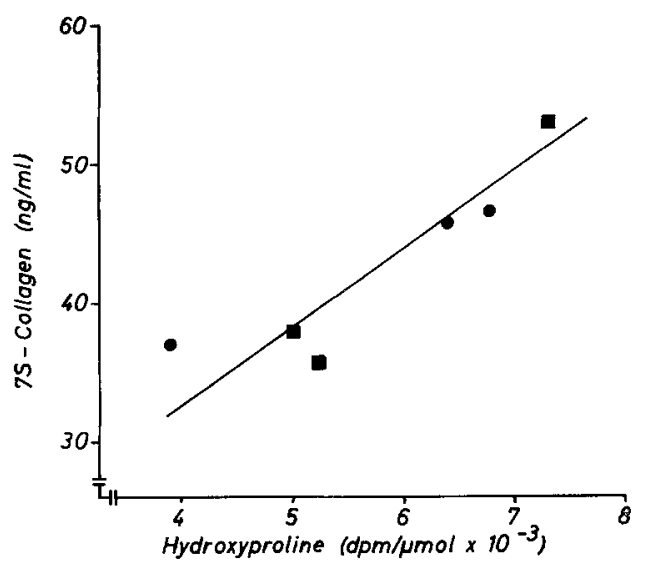

Fig.3. Correlation between serum concentration of $7 \mathrm{~S}$ collagen and collagen synthesis in renal basement membranes in diabetic rats 18 (O) or 34 (a) days after streptozotocin injection. Collagen synthesis was measured by determining specific activity of hydroxyproline. Each point represents the result of a pooled group of five animals from the experiments after $18(\bullet, O)$ or $34(\square, \square)$ days of diabetes scribed by Brownlee and Spiro [2]. The ratio of the areas under the curve of specific activity for normal and diabetic rats was calculated and found to be 1.38 in younger (duration of diabetes 4 days) and 1.79 in older rats (duration of diabetes 18-34 days). The proline and hydroxyproline activities measured in the diabetic basement membranes were corrected by the corresponding factor.

The basement membranes isolated from glomeruli of rats of varying age and duration of diabetes were equally pure as judged by their phosphorous content (Table 2), which is a sensitive parameter of contamination by cellular material [20]. The concentration of amino acid characteristics for collagenous subunits of the isolated basement membrane did not differ in the diabetic and non-diabetic groups (Table 2). The composition of the remaining amino acids did not show any difference either in these groups (data not shown). However, formation of ${ }^{3} \mathrm{H}$-hydroxyproline was elevated by $54 \%$ in the diabetic rats 18 and 34 days after streptozotocin injection, when compared with controls $(p<$ 0.02 ; Table 3 ). Incorporation of ${ }^{3} \mathrm{H}$-proline was only slightly raised 18 and 34 days after induction of diabetes $(37 \%, p<0.05)$. The concentration of $7 \mathrm{~S}$ collagen in serum was also $74 \%$ higher in both diabetic groups than in the controls $(p<0.01$, Table 3$)$.

All these relative changes in basement membrane synthesis and $7 \mathrm{~S}$ collagen were not observed in rats made diabetic for only 4 days (Table 3 ). Since in this experiment both the experimental and control animals were younger by 4 weeks, both groups showed higher synthetic activity and serum $7 \mathrm{~S}$ collagen levels when compared with experiments in older rats [14].

A close correlation was observed between the specific hydroxyproline activity of basement membrane and the level of blood glucose in the diabetic rats 18 and 34 days after streptozotocin injection $(r=0.98 ; p<0.01$; Fig. 2). A similar correlation was found between serum $7 \mathrm{~S}$ collagen and glucose concentration $(r=0.88 ; p<$ 0.01 ; Fig. 2) or formation of ${ }^{3} \mathrm{H}$-hydroxyproline $(r=0.91 ; p<0.01$; Fig. 3$)$. No significant correlation could be found between proline incorporation into the basement membrane and serum $7 \mathrm{~S}$ collagen concentration or blood glucose. 


\section{Discussion}

$7 \mathrm{~S}$ collagen is a characteristic domain of basement membrane (type IV) collagen and part of it is released into the circulation during basement membrane metabolism and can be measured in serum by radioimmunoassay [14]. It is likely that the serum component resembles monomeric type IV collagen or procollagen which both possess the $7 \mathrm{~S}$ collagen domain $[10,19]$. Thus, the circulating form of $7 \mathrm{~S}$ collagen presumably reflects the formation and turnover of basement membrane collagen in the body. Induction of diabetes in rats by streptozotocin raised the serum concentration of $7 \mathrm{~S}$ collagen within 2 weeks [15], and in these animals this rise preceded the morphologically detectable thickening of the capillary basement membrane by several months $[11,18]$. It is not known whether increased synthesis or decreased degradation contribute to elevated serum levels.

In the present study, we have measured glomerular basement membrane synthesis in vivo in diabetic and normal rats by injection of labelled proline [2]. Previously described differences in the precursor pool $[2,4]$ were confirmed by this study and taken into account by determining the specific activity curves of serum proline after injection of the tracer. The possible reasons for the lower specific activity of serum proline in diabetes have been discussed in detail elsewhere $[2,4,6]$. The factors considered so far have been an increased excretion of the radioactive precursor pool [4] or a dilution of the injected tracer. The latter might have occurred either from the enlarged intra- and extravascular volume of diabetic rats [7] or by a larger proline pool resulting from accelerated gluconeogenesis in untreated diabetes [2]. The difference between the specific serum proline activity in diabetic and non-diabetic rats could be abolished in renal tissue by an increased glomerular filtration rate observed in streptozotocin-diabetic rats, which may favour renal exposure to circulating ${ }^{3} \mathrm{H}$-proline [9]. However, in diabetic rats the specific proline activity of renal cortex is also lowered to the same extent as in serum [2]. The difference in age and duration of diabetes did not influence the purity of basement membrane preparation, as judged by the low phosphorous content and the typical amino acid composition of the isolated basement membranes.

As predicted from a previous study [17], an age-related decrease of basement membrane synthesis was observed in diabetic and non-diabetic groups. However, the formation of hydroxyproline as a specific parameter of collagen synthesis was markedly raised in diabetic rats 18 and 34 days after streptozotocin injection, when compared with metabolically healthy controls. This observation is in agreement with previously published data $[2,4,6]$. Incorporation of proline, as a parameter of total protein synthesis in the basement membrane, was much less elevated in these streptozotocin-diabetic rats. The increase of hydroxyproline activity was distinctly higher than the increase in proline incorporation and most of the latter can be attributed to the proline content of type IV collagen [19]. This shows that the synthesis of the collagen portion of glomerular basement membrane is influenced more by the metabolic disorder than the synthesis of the non-collagenous proteins. However, this alteration of basement membrane metabolism could not be detected in rats with short-term diabetes ( 4 days), even though blood glucose was increased threefold in these animals.

The concentration of 7S collagen in the sera of diabetic and non-diabetic rats also showed an age-related decrease resembling that observed in basement membrane synthesis. As expected from a previous study [15], the $7 \mathrm{~S}$ collagen level was markedly raised in diabetic rats compared with controls 18 and 34 days after streptozotocin injection. Furthermore, a positive correlation was found with basement membrane collagen synthesis. A renal insufficiency or exsiccosis of the diabetic animals could account for the serum changes observed. However, the creatinine values were normal and Ilstrup et al. [7] showed previously that diabetic rats did not display a lowered intravascular or extravascular volume when they had free access to water. An increased degradation of the basement membrane with a large release of $7 \mathrm{~S}$ collagen or related structures is probably not responsible for the elevated levels, since the turnover of basement membranes is slowed down in diabetes $[4,16]$. A decrease in the disappearence rate of $7 \mathrm{~S}$ collagen in diabetes which could lead to raised serum levels was not observed after injection of radiolabelled $7 \mathrm{~S}$ collagen (D. Brocks, personal communication). Thus, the data indicate that analysis of circulating forms of type IV collagen may be useful in evaluating basement membrane synthesis occurring elsewhere in the vascular system.

A significant correlation was also found for $7 \mathrm{~S}$ collagen or glomerular collagen synthesis and the blood glucose levels except in the young diabetic animals. With increasing glucose levels, synthesis of basement membrane collagen and serum 7S collagen concentration rose. Previously it has been shown that improvement of metabolic control in diabetic rats by insulin treatment normalized basement membrane synthesis [3, 5] and 7S collagen [15]. Therefore, these findings indicate that the degree of the metabolic dysregulation has an influence on basement membrane synthesis. However, the failure of a corresponding correlation in shortterm diabetic rats suggests that the alteration of basement membrane metabolism does not occur simultaneously with induction of diabetes.

\section{References}

1. Bartlett GR (1959) Phosphorus assay in column chromatography. J Biol Chem 234: 466-469

2. Brownlee M, Spiro RG (1979) Glomerular basement membrane metabolism in the diabetic rat. In vivo studies. Diabetes 28 : $121-125$ 
3. Cohen MP, Khalifa A (1977) Renal glomerular collagen synthesis in streptozotocin diabetes. Biochem Biophys Acta 500:395-404

4. Cohen MP, Surma ML, Van-Yu Wu (1982) In vivo biosynthesis and turnover of glomerular basement membrane in diabetic rats. Am J Physiol 242: F395-F389

5. Hasslacher Ch, Wahl P (1980) Influence of diabetes control on synthesis of protein and basement membrane collagen in isolated glomeruli of diabetic rats. Res Exp Med 176: 247-253

6. Hasslacher Ch, Kopischke HG, Bürklin E, Gechter F, Reichenbacher R (1982) In vivo studies on basement membrane synthesis in diabetic and non-diabetic rats. Res Exp Med 181: 245-251

7. Ilstrup KM, Keane WF, Michels LD (1981) Intravascular and extracellular volumes in the diabetic rat. Life Sciences 29: 717-724

8. Meezan E, Hjelle K, Brendel K, Carlson EC (1975) A simple, versatile, nondisruptive method for the isolation of morphologically and chemically pure basement membranes from several tissues. Life Sciences 17: 1721-1732

9. Michels LD, Davidman M, Keane WF (1981) Determinants of glomerular filtration and plasma flow in experimental diabetic rats. J Lab Clin Med 98: 869-885

10. Oberbäumer I, Wiedemann H, Timpl R, Kühn K (1982) Shape and assembly of type IV procollagen obtained from cell culture. Embo J 1: 805-810

11. Rasch R (1979) Prevention of diabetic glomerulopathy in streptozotocin-diabetic rats by insulin treatment. Glomerular basement membrane thickness. Diabetologia 16:319-324

12. Risteli J, Bächinger HP, Engel J, Furthmayr H, Timpl R (1980) 7S collagen: characterization of an unusual basement membrane structure. Eur J Biochem 108: 239-250

13. Risteli J, Wick G, Timpl R (1981) Immunological characterization of the 7-S collagen domain of type IV collagens. Coll Relat Res 1: 419-432
14. Risteli J, Rohde H, Timpl R (1981) Sensitive radioimmunoassay for 7-S collagen and laminin application to serum and tissue studies of basement membranes. Anal Biochem 113: 372-378

15. Risteli J, Draeger KE, Regitz G, Neubauer HP (1982) Increase in circulating basement membrane antigens in diabetic rats and effects of insulin treatment. Diabetologia 23: 266-269

16. Romen W, Heck T, Rauscher G, Lange HU, Hempel K (1980) Glomerular basement membrane turnover in young, old and streptozotocin-diabetic rats. Renal Physiol 3: 324-329

17. Spiro RG, Spiro MJ (1971) Studies on the biosynthesis of the hydroxylysine-linked disaccharide unit of basement membranes and collagens. J Biol Chem 216: 4919-4925

18. Steffes MW, Brown DM, Basgen JM, Matas AJ, Mauer SM (1979) Glomerular basement membrane thickness following islet transplantation in the diabetic rat. Lab Invest 41:116-118

19. Timpl R, Wiedemann H, van Delden V, Furthmayr H, Kühn K (1981) A network model for the organization of type IV collagen molecules in basement membranes. Eur J Biochem 120: 203-211

20. Westberg NG, Michael AF (1970) Human glomerular basement membrane. Preparation and composition. Biochemistry 9: $3837-3846$

Received: 14 February 1983

and in revised form: 24 October 1983

Dr. Ch. Hasslacher

Medizinische Universitåtsklinik

Bergheimerstraße 58

D-6900 Heidelberg 1, FRG 